\title{
Bioinformatics Research Through Image Processing of Histopathological Response to Stonefish Venom
}

\author{
Mohammad Wahsha ${ }^{1}$ * \\ Marine Science Station, The University of Jordan \\ Aqaba Branch, Jordan
}

\author{
Heider A. M. Wahsheh ${ }^{2}$ \\ Department of Information Systems \\ College of Computer Sciences and Information Technology \\ King Faisal University, Al-Ahsa, Saudi Arabia
}

\author{
Wissam Hayek ${ }^{3}$, Maroof Khalaf ${ }^{5}$, Tariq Al-Najjar ${ }^{6}$ \\ Faculty of Basic and Marine Sciences \\ The University of Jordan, Aqaba Branch, Jordan
}

\author{
Haya Al-Tarawneh ${ }^{4}$ \\ Control Health Division \\ Aqaba Special Economic Zone Authority \\ Aqaba, Jordan
}

\begin{abstract}
The present study utilizes coastal and environmental engineering to investigate the histopathological effects of Synanceia verrucosa venom on Albino BALB/c mice. S. verrucosa is the most hazardous venomous marine fish that belong to the family Synanceiidae, generally known as the "Reef Stonefish". Crude venom was collected from venom glands of the dorsal spines of stonefish samples taken from the Jordanian coastline of the Gulf of Aqaba, Red Sea. The mice were given intramuscular injections of the venom. Consequently, the research evaluated the acute toxicity and influence on selected serum biomarker enzymes, as well as possible histological alterations of the soleus skeletal muscles. The mice $24 \mathrm{~h} \mathrm{LD} \mathrm{D}_{50}$ was $0.107 \mu \mathrm{g}$ toxin/ $\mathrm{kg}$ mouse body weight. After the treatment using venom sublethal dose, the serum biomarkers, including Lactate dehydrogenase (LDH) and Alanine aminotransferase (ALT), were significantly improved $(\mathrm{P} \leq \mathbf{0 . 0 5})$. In addition, Lipid Peroxidation (LPO) contents were significantly increased $(P \leq 0.05)$ after venom treatment. Moreover, we combined routine medical procedures and artificial intelligence-assisted image analysis for a rapid qualitative and quantitative diagnosis of stonefish injury, based on the histophotography of mice tissue samples during the observation period $(1,2$, and 3 hours respectively). The novelty of our method is that we could detect severe and mild damage with an accuracy of $93 \%$ and $91 \%$, respectively. The most histological abnormalities in muscles were the great variety in diameters, content, and widespread among randomly distributed muscle fibres. In addition, loss of the tissue's striated appearance was noticed in toxin-treated groups compared with the control group. Consequently, our findings indicate the Stonefish's harmful influences that may endanger human life and highlight the need for appropriate measures to be considered. This, in turn, can ensure beach safety in the Gulf of Aqaba.
\end{abstract}

Keywords-Synanceia verrucosa; Gulf of Aqaba; artificial intelligence; marine biotoxins

\section{INTRODUCTION}

Injuries by stingrays from dangerous marine organisms are common in coastal and lakesides regions worldwide [1]. These injuries can threaten life and affect body organs and systems [2]. According to several reports, there is a potential for more severe injuries, particularly with stonefish and stingray envenomation [3]. Stonefish belong to the genus Synanceia, considered one of the most venomous fish in the world. It can be found in tropical waters (Pacific Ocean, Indian Ocean, and the Red Sea) [3, 4]. The stonefish defense system comprises 17 spines covered with thick skin supported by venom glands $[5,6]$. It is found in the shallow water near the bottom [7]. Using its pectoral fins, Stonefish can rapidly dredge in the mud or the seabed sand in which it settles down and lays motionless [8]. It has a solid ability to camouflage and blend in so perfectly with its surroundings, enhancing its hiding ability $[6,7]$. Their ability to hide under the sand or between coral makes them challenging to detect and avoid, which increases the chances of injury by their stings [4]. [9] reported two cases of injuries from Stonefish in the north of Australia; one of these cases occurred with a 16 years old girl who presented hysterical screaming from pain severity. She impaled her big toe on the spine of a fish in the water. There was a puncture wound on the tip of the toe. The whole toe was cyanosed and swollen. Large doses of pethidine failed to control her pain. A ring block was inserted in the toe, and the Stonefish antivenom was administered with good effect. She was discharged the next day and did not suffer a sequel.

In general, injuries from the venom of the stonefish sting diversify considerably. It can vary from intense pain, which may persist for several hours or even days, redness and swelling in the sting site followed by shock, pulmonary edema, hypotension, bradycardia, arrhythmia, cardiovascular collapse, muscles weakness, paralysis, convulsions, to occasional death in severe cases $[5,10]$. Damage to cells can occur as a result of stresses such as toxins and venoms [8]. Most observable cellular changes and cell deaths occur due to biochemical changes within the cell [11]. Releasing the intracellular enzymes has been a marker of cell damage in various injury cases [12]. Increasing ALT activity level has been associated with organ toxicities [13]. LDH is a cytoplasmic enzyme that catalyzes lactate oxidation into pyruvate and reverses, predominantly in muscle tissues [11]. Histology is also crucial in pathology; it characterizes changes or disease phenotypes and diagnoses their causes [14]. Limited studies estimate the effect of piscine venoms on muscle. For example, [15] study the impact of Scatophagus 
Argus (family: Scatophagidae) venom on gastrocnemius muscle, were the venom-induced significant local tissue damage characterized by pain, edema, and necrosis and induced a rapid increment in serum creatine kinase and lactate dehydrogenase (LDH) showing the myotoxicity of venom.

Therefore, in this study, we aimed to evaluate the toxicity of stonefish venom on mice muscles using biochemical, histological, and image processing analysis.

\section{MATERIAL AND METHODS}

\section{A. Chemicals and Fish Sample}

All chemicals and reagents were of analytical grade and purchased from Sigma-Aldrich unless otherwise indicated. At least ten stonefish samples were collected by SCUBA diving from the northern side of the Gulf of Aqaba. Collected fish were identified as Synanceia verrucosa based on [7]. Fish were kept alive under the control condition in an oxygenated seawater aquarium at the Aquaculture unit of the Marine Science Station (MSS) located along the Jordanian Gulf of Aqaba.

\section{B. Experimental Animal}

Male Balb c/mice 6-7 weeks old (average body weight $25 \mathrm{gm})$ were used. Mice were obtained from the animal house at Yarmouk University located on the northern side of Jordan. They were maintained on a standard laboratory diet and tap water during the experiment period. The sampling activities on animals (fish and mice) were conducted after taking the required permissions from relevant public authorities and agreeing with the animal care and use legislations at the MSS.

\section{Isolation of Fish Crude Venom}

Crude venom was collected by inserting the rubber caps of test tubes into the dorsal spine of the sampled fish, considering reaching a suitable distance in the spine to extrude the required high viscous venom. A volume of 0.3-0.4 $\mathrm{ml}$ of venom was dissolved in $1 \mathrm{ml}$ phosphate buffer saline to get milky diluted venom. The concentration of the venom was calculated using the Bradford method as recommended by [4]. The extracted soluble crude venom was immediately stored in a dark container at $-20{ }^{\circ} \mathrm{C}$ for further biochemical and histological analysis. The concentration of the extracted venom was determined following [8].

\section{D. $L D_{50}$ Determination}

A modified up and down method was used to evaluate the intramuscular injection (i.m) $\mathrm{LD}_{50}$ value of the extracted venom using Balb/c mice in laboratory conditions [4]. A stock solution of crude stonefish venom was diluted several times (up to 30 times $\mathrm{V} / \mathrm{V}$ ). The experiment was set into triplicate groups of healthy mice $(n=3)$. Mice were observed for $24 \mathrm{~h}$ and symptoms of toxicity such as modifications for regular activities and the death time of injected mice were recorded.

\section{E. Mice Bioassay and Experimental Model}

Sixty male Balb/c mice were divided into two main groups: The first group (C) was the control group, intramuscular injected (i.m) with phosphate buffer saline without venom administration (15 mice). The second group (T) was the toxin-treated groups (45 mice); mice were administered by intramuscular injection (i.m) with $107 \mu \mathrm{g}$ stonefish venom $/ \mathrm{kg}$ mouse body weight (according to $\mathrm{LD}_{50}$ value) and divided into three sub-groups: (a) Fifteen mice were killed after $1 \mathrm{hr}$ (T1). (b) Fifteen mice were killed after 2hrs. (T2) and (c) Fifteen mice were killed after 3hrs. (T3).

Blood samples were collected into a vial without anticoagulant from each mouse via cardiac puncture. The serum was separated by centrifugation at $3000 \mathrm{X} \mathrm{g}$ for $30 \mathrm{~min}$ and kept at $-4^{\circ} \mathrm{C}$ for the enzyme activity assays. The levels of serum lactate dehydrogenase (LDH) and Alanine aminotransferase (ALT) were measured at Sukaina Specialized Medical Labs in Amman, Jordan, using SigmaAldrich activity assay kits.

Moreover, soleus muscles were removed immediately after decapitation. They were divided into two groups: The first group was perfused with normal saline containing heparin and homogenized with phosphate buffer saline $(\mathrm{pH}$ 7.2). The perfused samples were kept in dark plastic bottles and stored at $-20^{\circ} \mathrm{C}$ for the LPO assay. The lipid peroxidation levels of the skeletal tissues were analyzed based on [16]. The second group was served for the microscope study and analysis. Small pieces of the heart were treated with formalin for fixation from all groups. Heart portions were dehydrated and embedded according to the procedures described by [17]. Tissue sections $(7 \mu \mathrm{m})$ were stained using Hematoxylin and Eosin $(\mathrm{H} \& \mathrm{E})$ and analyzed under the light microscope, according to $[17,18]$.

\section{F. Histopathological Image Analysis using Image-Processing Techniques}

Consequently, our obtained digitized sections of muscle tissue histopathology were amenable to the application of computerized image analysis and machine learning techniques. Besides, Artificial intelligence for image analysis has been utilized to distinguish possible muscle tissue injury after exposure to stonefish venom.

The model framework was designed on the assumption that its outputs were based on the following indices:

- Collect dataset of histopathological and benign images.

- Extract Features.

- Evaluate the artificial intelligence model using prediction quality metrics.

At least one hundred histological photographs have been used to build the model dataset; since then, this dataset has been computerized based on three-class labels; Mild, Moderate, and Severe. Artificial intelligence applies an image filter to extract image features such as corners, edges, colors, histograms, regions of interest points, and ridges [19]. Furthermore, the Support Vector Machine (SVM) algorithm was applied to build a model that analyses our histophotograph and classifies them into the three main classes (Mild, Moderate, and Severe). Prediction quality metrics were also applied to evaluate the performance of the SVM model, 
which includes: True Positive (TP), True Negative (TN), False Positive (FP), False Negative (FN), Precision, Recall, and FMeasure (F-M) [20, 21]. The following formulas present the main metrics:

$$
\begin{aligned}
& \text { Accuracy }_{i}=\frac{T P+T N}{T P+F P+T N+F N} \\
& \text { Recall }_{i}=\frac{T P}{T P+F N}
\end{aligned}
$$

Precision $_{i}=\frac{T P}{T P+F P}$

$$
F-\text { measure }=\frac{2 T P}{2 T P+F P+F N}
$$

\section{G. Statistical Analysis}

Statistical analysis was based on ANOVA and is presented as means \pm S.D. Statistical significance was considered at a pvalue of 0.05 or less. The data were analyzed statistically using Sigma Stat statistical software version 3.5.

\section{RESUltS}

The stonefish crude venom concentration was calculated using the standard curve to be $4.47 \mu \mathrm{g} / \mathrm{ml}$. The approximate $\mathrm{LD}_{50}$ of the extracted toxin was $107 \mu \mathrm{g}$ venom $/ \mathrm{kg}$ mouse body weight. The behavior of the venomous treated mice could be clearly distinguished by losing their energetic activity, nausea and vomiting, diarrhea, vertigo, fainting, convulsions, and spastic paralysis in the late stage.

\section{A. Effect of the Stonefish Venom on the Enzymatic Profile}

The changes in serum biochemical markers LDH and ALT levels are presented in Fig. 1 and 2, respectively. In treated mice with the venom, the serum LDH and ALT levels showed significant $(\mathrm{P} \leq 0.05)$ increased after 1 hour of venom administration and continued to rise until three hours. Moreover, it was notable that the effect of stonefish venom on mice's skeletal muscles was time-dependent. As shown in Fig. 1: the treated groups produced nearly one-fold after 1 hour, 12 and 21-fold after 2 and 3 hours after venom exposure, respectively.

Fig. 1 presents the LDH activity in mice muscle tissue. C: Control group, T1: Toxin group after 1hr, T2: Toxin group after $2 \mathrm{hrs}$ and T3: Toxin group after $3 \mathrm{hrs}$, for mice tissues from muscle. Presented data are mean values (units per liter) for each group of mice \pm S.D.

Correspondingly, the mice muscles that received stonefish venom revealed an increase in ALT value by a fold of almost 9 in the case of $\mathrm{T} 1$ and $\mathrm{T} 2$ when compared to the control group (Fig. 2). A further increase was shown as 13 -fold in toxin group $\mathrm{T} 3$ compared with the controls $(\mathrm{P} \leq 0.05)$.

Fig. 1 presents the trend of change in ALT activity in tissues of mice muscle. C: Control, T1: Toxin group after $1 \mathrm{hr}$, T2: Toxin group after $2 \mathrm{hrs}$ and T3: Toxin group after $3 \mathrm{hrs}$.
Presented data are mean values (units per liter) for each group of mice \pm S.D.

On the other hand, Malondialdehyde (MDA) produced oxidative damage to lipids. MDA concentration in tissue homogenate is mainly used as a biomarker for tissue damage. Control mice (group C) exhibited normal lipid peroxidation (MDA) levels, $7.3 \mu \mathrm{M} / \mathrm{g}$ in muscles homogenate. However, after that venom administration, a dramatic irregular trend of MDA production was observed due to rapid and severe tissue damage (Fig. 3).

Fig. 3 shows the trend of change in MDA mean concentration $\left(\mu \mathrm{Mg}^{-1}\right)$ for mice muscles. C: Control mice group, T1: Toxin group after $1 \mathrm{hr}, \mathrm{T} 2$ : Toxin group after $2 \mathrm{hrs}$ and T3: Toxin group after $3 \mathrm{hrs}$, presented value are mean value \pm S.D. $(n=7)$.

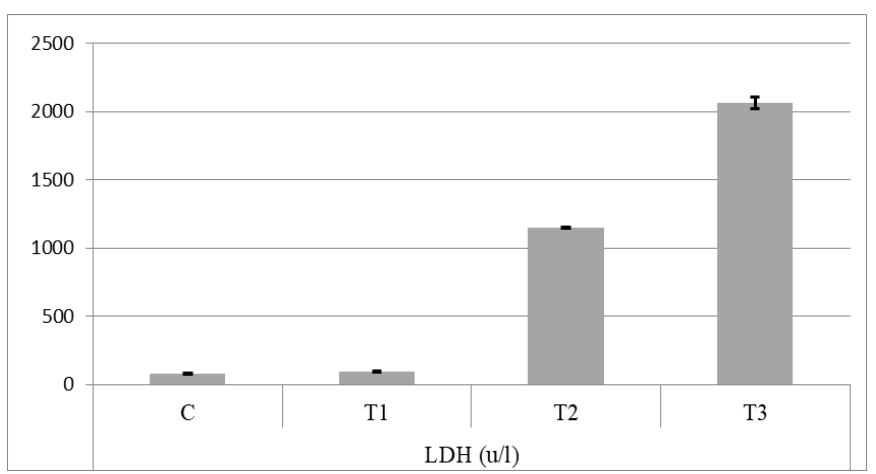

Fig. 1. The Treated Groups after Venom Exposure, respectively.

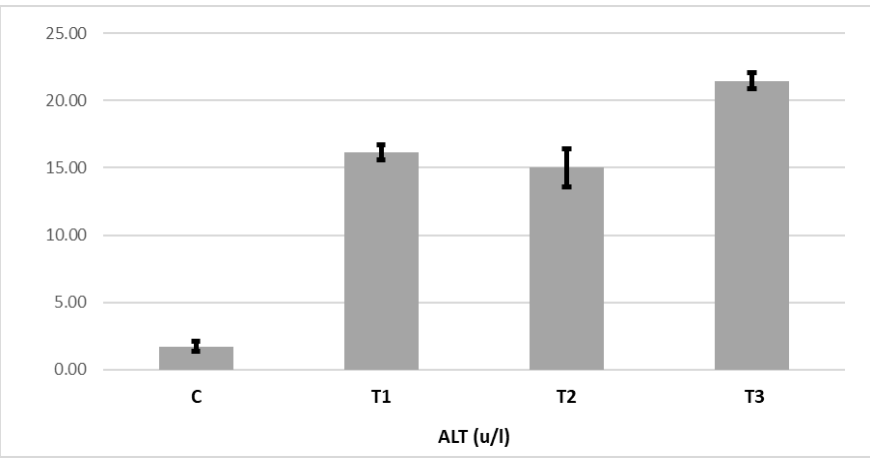

Fig. 2. The Trend of Change in ALT Activity in Tissues of Mice Muscle.

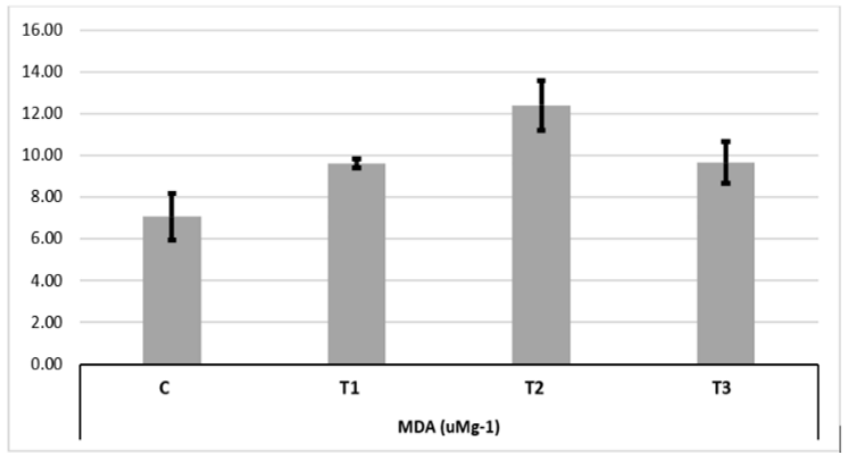

Fig. 3. The Trend of Change in MDA means Concentration $\left(\mu \mathrm{Mg}^{-1}\right)$ for Mice Muscles. 


\section{B. Histopathological Observations}

We have revealed that the histo-structure of the skeletal muscle is highly disturbed under the influence of the stonefish venom. The most apparent histological abnormalities in muscles were the great variety of diameters, content, and widespread among randomly distributed muscle fibres. In addition, loss of the fibers' striated appearance can appear in venom-treated groups compared with the control group (Fig. 4). Muscle fibers of the control group show higher content and widespread fibres compared with the treatment groups. (H\&E, 10X). C: Control group, T1: Toxin group at $1 \mathrm{hr}$, T2: Toxin group at $2 \mathrm{hrs}$, T3: Toxin group at $3 \mathrm{hrs}$. *: Inflammation.
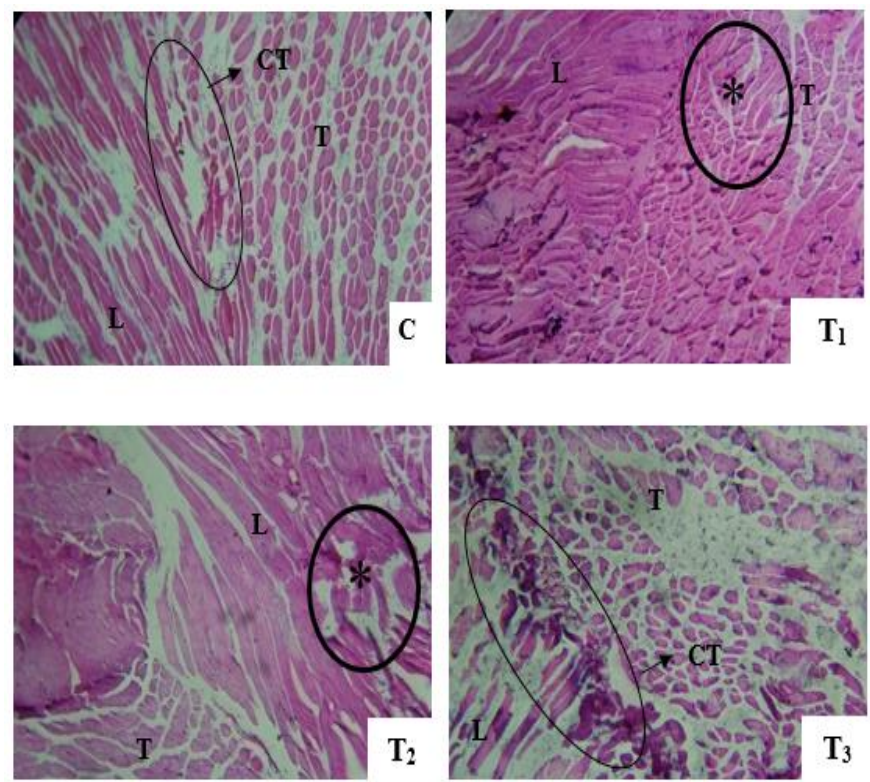

Fig. 4. The Histopathological Changes in Muscles of Venom Injected ( $\left.\mathrm{LD}_{50}\right)$ Mice Compared with the Control Mice.

Moreover, Fig. 5 illustrated the histopathological changes in muscles of venom-treated mice compared with the control group.
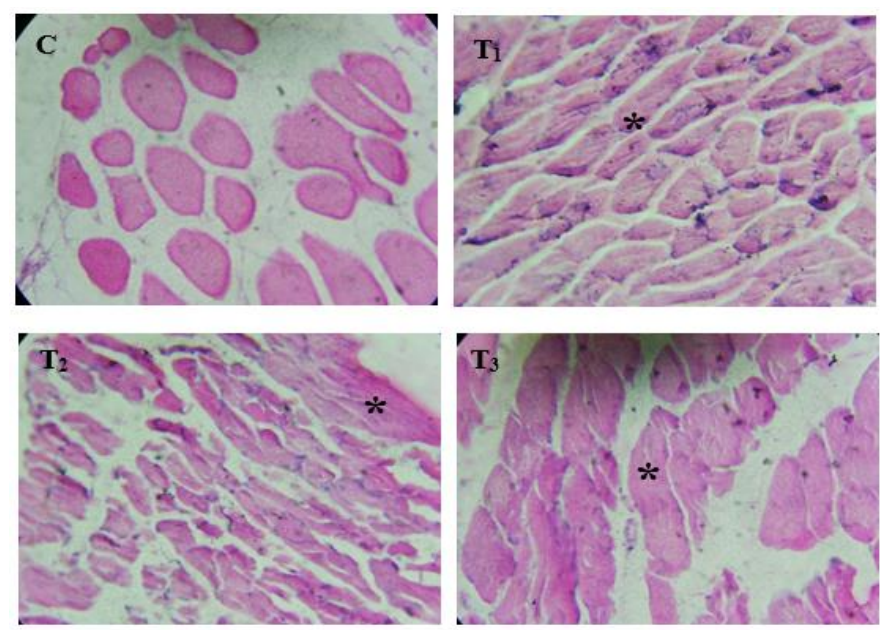

Fig. 5. The Histopathological Changes in Muscles of Venom-Treated $\left(\mathrm{LD}_{50}\right)$ Mice Compared with the Control Mice.
Control mice muscle reveals a widespread in muscle fibres. Venom treated muscles showing inflammation, degradations, and loss of the striated appearance of the protein fibers. (H\&E, 40X). C: Control group, T1: Toxin group at $1 \mathrm{hr}$, T2: Toxin group at 2hrs, T3: Toxin group at $3 \mathrm{hrs}$. *: Inflammation.

\section{Histopathological Image Analysis}

Previous sections demonstrated the experimentally routine procedures for evaluating the possible harmful effects of stonefish venom on male BALB/c mice's skeletal muscles. Although the histopathological photographs' investigation was performed manually, this technique is time-consuming and depends on the investigator's experience. Therefore, artificial intelligence-assisted image analysis was suggested for qualitative and quantitative diagnosis of skeletal muscle tissues in order to overcome the time challenge. Consequently, our results showed that the SVM model accuracy could detect severe and mild damage with $93 \%$ and $91 \%$, respectively, according to the used dataset with promising accuracy results. Table I shows the SVM model's detailed prediction metrics.

TABLE I. DETAILED RESUlTS OF THE SVM MODEL

\begin{tabular}{|l|l|l|l|l|l|}
\hline Class & TP & FP & Precision & Recall & F-M \\
\hline Mild & 0.80 & 0.077 & 0.80 & 0.80 & 0.80 \\
\hline Moderate & 0.909 & 0.040 & 0.909 & 0.909 & 0.909 \\
\hline Severe & 0.933 & 0.48 & 0.933 & 0.933 & 0.933 \\
\hline $\begin{array}{l}\text { Weighted } \\
\text { Average }\end{array}$ & 0.889 & 0.053 & 0.889 & 0.889 & 0.889 \\
\hline
\end{tabular}

TP: True Positive, FP: False Positive, and F-M: F-Measure

True Positive classifies images correctly to their original class labels, while False Positive incorrectly classifies images. Precision reflects the ratio of relevant images through the retrieved. Recall means the percentage of the relevant images that the model retrieved. The F-Measure is the harmonious average of precision and recall. It is a composed metric that penalizes extreme values and provides a single measurement for a system that illustrates optimization. The SVM results showed that artificial intelligence offers accurate models to be applied in the natural environment. Therefore, it can support researchers and medicals in recognizing the appearance of particular health issues after stonefish envenomation and assist in the production of fast, reliable, and economical technologies.

\section{DISCUSSION}

This study investigates the adverse effect of stonefish crude venom using biochemical and histological approaches on mice muscles. Serum LDH values showed a significant increase $(\mathrm{P} \leq 0.05)$ by 12 and 21 -fold in the T2 and T3 groups, respectively, compared with the control group. These results are reasonable in which a suitable explanation could be rendered by the regulatory mechanism of $\mathrm{LDH}$ in the muscles. $\mathrm{LDH}$ is regulated by the relative concentrations of its substrates $[11,22]$. LDH becomes more active under periods of extreme muscular output due to the increase in substrates for the $\mathrm{LDH}$ reaction [4, 22]. When skeletal muscles are forced to produce high levels of energy, the demand for 
Adenosine Triphosphate (ATP) in regards to aerobic ATP supply leads to an accumulation of free Adenosine Diphosphate (ADP), Adenosine Monophosphate (AMP), and inorganic phosphate (Pi) [22]. The subsequent glycolytic flux, specifically the production of Nicotinamide adenine dinucleotide (NADH) and pyruvate, exceeds the capacity for pyruvate dehydrogenase and other shuttle enzymes to metabolize pyruvate. The flux through LDH increases in response to increased pyruvate and NADH to metabolize pyruvate into lactate [22-24].

Furthermore, the results show a significant increase in ALT activity after stonefish venom injection, proving muscle toxicity and cell-damaging, which agreed with [12] and [13]. Moreover, the results showed an increase in MDA level in the homogenate tissue of the toxin groups, as highly reactive molecules are responsible for the development of several and different diseases [23, 25]. Our finding proves that there are cytotoxicity and cellular damage, in agreement with [26, 27].

The most apparent histological abnormalities in muscle tissue are reflected by losing their striated appearance. In addition, there was a variation in the diameters, content, widespread among randomly distributed muscle fibres and inflammation in fibres. Thus, our histological studies confirmed that the stonefish venom produced marked pathological changes consistent with extensive damage to the muscle fibers of the mice. The latter finding agrees with a similar study by [5], where it was reported that the proteaserelated activities of stonefish crude venoms are probably responsible for tissue necrosis and the spread of venom toxicity. It usually consists of depolarising action (stressinducing imbalance) of cell membrane on both nerve and muscle tissues, and that their effects differ only quantitatively $[25,28,29]$. Based on our findings, we hypothesized the role of stonefish venom in cell signaling (ROS dependent) that might interact with the biological consequences processes.

As presented previously, histological photomicrographs can be procured by using technoscientific digital cameras connected with a microscope to identify tissue formation and structure abnormalities under the microscope. Recently, automated artificial intelligence algorithms can be utilized to distinguish abnormal characteristics based on a specific symptom. In agreement with other related studies [30, 31, 32], artificial intelligence has shown dramatic growth in environmental monitoring and medical health applications, mainly in enhancing histopathology imagery, which can provide a breeding ground for developing bioinformatics applications in various fields.

\section{CONCLUSION}

Our observations on rapid skeletal muscle damage and inflammation induced by stonefish venom permit us to highlight the need to maintain adequate antivenom stocks in the hospitals in Aqaba. Moreover, we illustrated the benefits of using digital image processing techniques for stonefish histology image analysis by developing a predictive set of tools to aid researchers and medicals in identifying the appearance of specific health problems after stonefish envenomation and provide fast, reliable, and economical technologies. Further coastal and environmental engineering investigations on dangerous marine organisms: their distribution, habitat, and ecotoxicity along the Jordanian coast of the Gulf of Aqaba, can prove to be promising towards ensuring beach safety in the Gulf of Aqaba.

\section{REFERENCES}

[1] V. Haddad, H.O. Stolf, J.Y. Risk, F.O. França, and J.L.C. Cardoso, "Report of 15 injuries caused by lionfish (Pterois volitans) in aquarists in Brazil: a critical assessment of the severity of envenomations," Journal of venomous animals and toxins including tropical diseases, vol. 21, pp. 1-7, 2015.

[2] M. Wahsha, H. Al-Tarawneh, M. Khalaf, W. Hayek, M. Sbaihat, and T. Al-Najjar, "Cardiovascular responses to Stonefish Synanceia verrucosa venom in balb/c mice," Fresenius Environmental Bulletin, vol. 30(2), pp. 891-898, 2021.

[3] S.L. Saggiomo, C. Firth, D.T. Wilson, J. Seymour, J.J. Miles, Y. Wong, "The Geographic Distribution, Venom Components, Pathology and Treatments of Stonefish (Synanceia spp.) Venom," Marine Drugs, vol. 19(6), pp. 302, 2021

[4] A. Khalil, M. Wahsha, K. Khadra, M. Khalaf, and T. Al-Najjar, "Biochemical and histopathological effects of the stonefish (Synanceia verrucosa) venom in rats," Toxicon, vol. 142, pp. 45-51, 2018.

[5] K.M. Poon, C.H.V. Ng, M.L. Tse, "A 10-year retrospective review of stonefish sting injury in Hong Kong," Hong Kong Journal of Emergency Medicine, vol. 27, pp. 300-303, 2020.

[6] F. V. Campos, T. N. Menezes, P. F. Malacarne, F. L. Costa, G. B. Naumann, H. L. Gomes, and S. G. Figueiredo, "A review on the Scorpaena plumieri fish venom and its bioactive compounds," Journal of Venomous Animals and Toxins including Tropical Diseases, vol. 22, pp. 1-9, 2017.

[7] M. Khalaf, and A. Disi, "Fishes of the Gulf of Aqaba," 1sted. Marine Science Station Publication, pp. 64-68, Jordan, 1997.

[8] M. Wahsha, H. Al-Tarawneh, M. Khalaf, T. Al-Najjar, and W. AlZyoud, "Histological and functional renal alterations caused by Synanceia verrucosa venom in Mice," Fresenius Environmental Bulletin, vol. 28(7), pp. 5294-5300, 2019.

[9] G. Taylor, "Toxic fish spine injury: Lessons from 11 years' experience," Spums Journal, vol. 30(1), pp. 7-8, 2000.

[10] T.Y Chen, Y.H. Chang, H.P. Lin, S.T. Chen, and D.F. Hwang, "Proteomic Identification of Stonefish Synanceja verrucosa Venom," Journal of Food and Nutrition Research, vol. 3(8), pp. 526-539, 2015.

[11] M. Wahsha, S. Al-Jassabi, M. Azirun, and K. Abdul-Aziz, "Biochemical screening of Hesperidin and Naringin against liver damage in Balb/c mice exposed to Microcystin-LR," Middle East Journal of Scientific Research. vol. 6(4), pp. 354-359, 2010.

[12] M. Kteifan, M. Wahsha, and F. Al-Horani, "Assessing stress response of Stylophora pistillata towards oil and phosphate pollution in the Gulf of Aqaba, using molecular and biochemical markers," Chemistry and Ecology, vol. 33(4), pp. 281-294, 2017.

[13] J. Ozer, M. Ratner, M. Shaw, W. Bailey, and S. Schomaker, "The current state of serum biomarkers of hepatotoxicity," Toxicology, vol. 245(3), pp. 194-205, 2008.

[14] P. M. Treuting, and S. M. Dintzis, "Comparative Anatomy and Histology: A Mouse and Human Atlas," $1^{\text {st }}$ ed USA, Elsevier, 2012.

[15] G. Sivan, K. Venketasvaran, and C. K. Radhakrishnan, "Characterisation of biological activity of Scatophagus argus venom," Toxicon, vol. 56(6), pp. 914-925, 2010.

[16] M. Wahsha, C. Bini, S. Fontana, A.Wahsha, and D. Zilioli, "Toxicity assessment of contaminated soils from a mining area in Northeast Italy by using lipid peroxidation assay," Journal of Geochemical Exploration, vol. 113, pp.112-117, 2012.

[17] H. Alhaj, "Principles of histology," 1st ed. Amman, Dar Almaseera for publishing, distribution and printing, 2013.

[18] H. Alhaj, "Optical Microscopic Preparations," 1st ed. Amman, Dar Almaseera for publishing, distribution and printing, 2010.

[19] H. Wahsheh, and M. Al-Zahrani, "Secure Real-Time Computational Intelligence System Against Malicious QR Code Links," International Journal of Computers Communications \& Control, 16(3), pp. 1-9, 2021. 
[20] S. Abdulateef, M. Mahmuddin, and N. Harun, "Shadow Identification in Food Images using Extreme Learning Machine," International Journal of Advanced Computer Science and Applications(IJACSA), vol. 8(8), pp. 68-74, 2017.

[21] H. Herle, and P. K V, "Relative Merits of Data Mining Algorithms of Chronic Kidney Diseases," International Journal of Advanced Computer Science and Applications(IJACSA), 12(6), 2021.

[22] L. Spriet, R. Howlett, and G. Heigenhauser, "An enzymatic approach to lactate production in human skeletal muscle during exercise," Medicine and science in sports and exercise, vol. 32(4), pp. 756-763, 2000.

[23] M. Wahsha, and S. Al-Jassabi, "The role of Silymarin in the protection of mice liver damage against Microcystin-LR toxicity," Jordan Journal of Biological Sciences, vol. 2(2), pp. 63-68, 2009.

[24] M. Wahsha, T. Al-Najjar, H. Al-Tarawneh, M. Khalaf, and S. Amer, "Biochemical and histological observations of lung injury after stonefish (Synanceia verrucosa) envenomation in BALB/c mice," Fresenius Environmental Bulletin, vol. 26(12), pp. 7204-7208, 2017.

[25] S. Bordbar, A. Ebrahimpour, A.Abdul Hamid, M. Y Abdul Manap, F. Anwar, and N. Saari, "The improvement of the endogenous antioxidant property of stone fish (Actinopyga lecanora) tissue using enzymatic proteolysis," Biomed Research International, pp. 1-9, 2013.

[26] E. Niki, "Lipid peroxidation: physiological levels and dual biological effects," Free Radical Biology and Medicine, vol. 47(5), pp. 469-484, 2009.
[27] R. Ziegman, P. Alewood, "Bioactive components in fish venoms," Toxins, 7(5): pp. 1497-531, 2015.

[28] J.Y.L. Lee, L.C. Teoh, S.P.M. Leo, "Stonefish envenomations of the hand-A local marine hazard: A series of 8 cases and review of the literature," Academy of Medicine Singapore, vol. 33, pp. 515-520, 2004.

[29] R.J. Harris, and R.A. Jenner, "Evolutionary ecology of fish venom: adaptations and consequences of evolving a venom system," Toxins, vol. 11(2), pp. 1-21, 2019.

[30] H. Wahsheh, and M. Al-Zahrani, "Secure and Usable QR Codes for Healthcare Systems: The Case of Covid-19 Pandemic," 12th International Conference on Information and Communication Systems (ICICS), pp. 324-329, 2021.

[31] S. Ayyad, M. Shehata, A. Shalaby, A. El-Ghar, M. Ghazal, M. ElMelegy, and A. El-Baz, "Role of AI and Histopathological Images in Detecting Prostate Cancer: A Survey," Sensors, vol. 21(8), pp. 2586, 2021.

[32] T. Tiyarattanachai,T. Apiparakoon, S. Marukatat, S. Sukcharoen, N. Geratikornsupuk, N. Anukulkarnkusol, P. Mekaroonkamol, N. Tanpowpong, P. Sarakul, R. Rerknimitr, and R. Chaiteerakij, "Development and validation of artificial intelligence to detect and diagnose liver lesions from ultrasound images," PLoS ONE, vol. 16(6), e0252882, 2021. 